Graphical Abstract

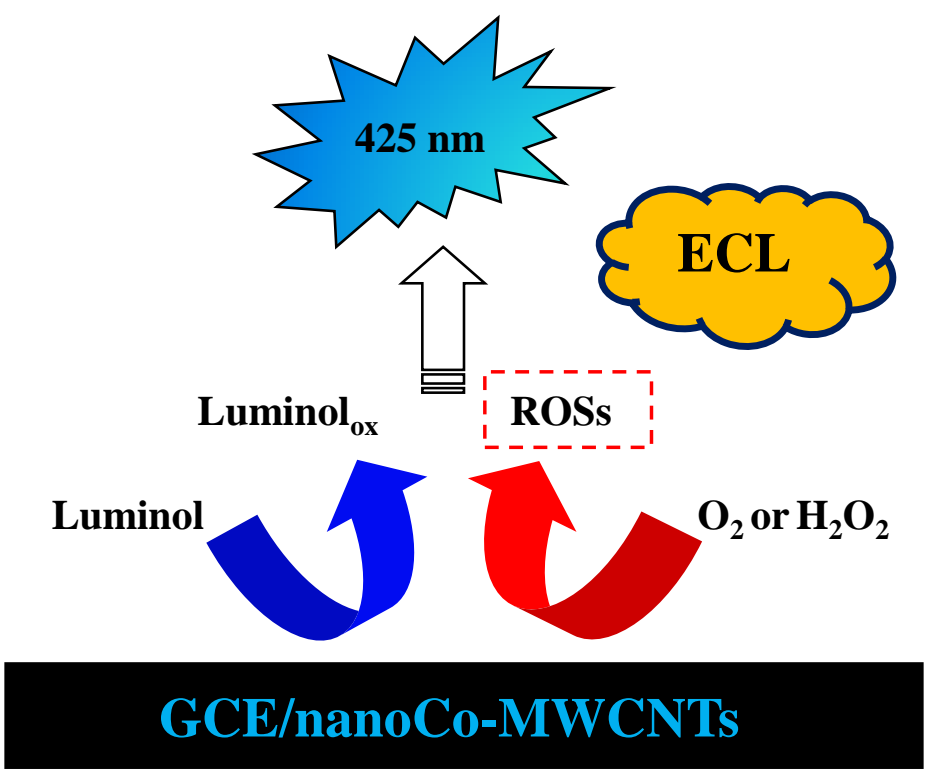




\title{
Improved electrogenerated chemiluminescence of luminol by cobalt nanoparticles decorated multi-walled carbon nanotubes
}

Behzad Haghighi* $^{* a, b}$, Azam Tavakoli ${ }^{\mathrm{b}}$ and Somayyeh Bozorgzadeh ${ }^{\mathrm{c}}$

${ }^{\text {a }}$ Department of Chemistry, College of Sciences, Shiraz University, Shiraz 71454, Iran.

${ }^{\mathrm{b}}$ Department of Chemistry, Institute for Advanced Studies in Basic Sciences, P.O. Box 451951159, Gava Zang, Zanjan, Iran.

${ }^{c}$ Department of Chemistry, Zanjan Branch, Islamic Azad University, P.O. Box 49195-467, Zanjan, Iran.

\begin{abstract}
Multi-walled carbon nanotubes (MWCNTs) were decorated with cobalt nanoparticles (CoNPs) by a simple thermal decomposition method. The prepared nanohybrid material (nanoCoMWCNTs) was then cast on the surface of a glassy carbon electrode (GCE) as a novel electrocatalyst for the construction of a sensitive electrochemiluminescence (ECL) sensor. The fabricated sensor (GCE/nanoCo-MWCNTs/Nafion) showed excellent electrocatalytic activity toward luminol and $\mathrm{H}_{2} \mathrm{O}_{2}$ oxidation reactions at neutral media. Under optimal experimental conditions, the ECL signal intensity of the sensor was linear with the concentration of luminol in the range between $80 \mathrm{nM}$ and $140 \mu \mathrm{M}(\mathrm{r}=0.9963)$ and also with the concentration of $\mathrm{H}_{2} \mathrm{O}_{2}$ in the range between $1 \mathrm{nM}$ and $240 \mu \mathrm{M}(\mathrm{r}=0.9980)$. Detection limits $(\mathrm{S} / \mathrm{N}=3)$ for luminol and $\mathrm{H}_{2} \mathrm{O}_{2}$ were 8.7 and $0.2 \mathrm{nM}$, respectively. The relative standard deviations (RSD) for repetitive
\end{abstract}

${ }^{*}$ Corresponding author, Tel: +98 713613 7178, Fax: +98 7136460724.

E-mail address: bhaghighi@shirazu.ac.ir (B. Haghighi) 
measurements of $100 \mu \mathrm{M}$ luminol $(\mathrm{n}=10)$ and $10 \mu \mathrm{M} \mathrm{H}_{2} \mathrm{O}_{2}(\mathrm{n}=11)$ were $1.6 \%$ and $2.0 \%$, respectively. Also, the prepared sensor was further modified with glucose oxidase (GOx) to fabricate a glucose ECL based biosensor (GCE/nanoCo-MWCNTs/GOx/Nafion). The fabricated ECL biosensor exhibited excellent performance toward glucose detection in the concentration range between 0.5 and $600 \mu \mathrm{M}$ with a satisfactory detection limit $(50 \mathrm{nM})$ and reproducibility $(2.3 \%)$

Keywords: Electrochemiluminescence; Multi-walled carbon nanotubes; Co nanoparticles; Luminol; Hydrogen peroxide; Glucose. 


\section{Introduction}

Electrogenerated chemiluminescence or electrochemiluminescence (ECL) is an attractive analytical tool with broad applications in different research areas. ECL is a hybrid technique which provides electrochemical and spectral information, simultaneously [1]. Simple and lowcost instrumental set up, excellent sensitivity and low background signal are the most important features of ECL $[2,3]$. A increased interest is observed for ECL investigations and this fact has been reflected in the number of reviews [4-9] which report the effectiveness of ECL detection method and its wide analytical applications.

Luminol (2, 3-aminophthalhydrazide) is the most popular organic luminescent species which can be oxidized at the electrode surface. The subsequent chemical reaction between the oxidized luminol and $\mathrm{H}_{2} \mathrm{O}_{2}$ (or $\mathrm{O}_{2}$ ) produces ECL signal. Since the first report on the observation of ECL response for luminol at the electrode surface in alkaline solution [10], numerous attempts have been done to find effective approaches for the enhancement of ECL signal intensity of luminol in neutral medium [11-14]. It has been shown that the ECL reaction of luminol with oxygen or hydrogen peroxide is more efficient in alkaline medium through modification of the electrode surface with nano-materials $[12,15]$.

With the development of nanotechnology, various types of nano-structured materials with outstanding properties are being synthesized and applied for the construction of novel sensors and biosensors. Nano-structured materials provide higher effective surface area and higher catalytic activity in comparison with their respective bulk materials. The catalytic effect of some nano-structured materials such as multi-walled carbon nanotubes (MWCNTs) [16, 17], Au nanoparticles (NPs) [18-20]; Pt-NPs [21], Ag-NPs [22-24] and $\mathrm{TiO}_{2}-\mathrm{NPs}$ [25] on chemiluminescence (CL) and ECL reactions have been investigated for luminol- $\mathrm{H}_{2} \mathrm{O}_{2}$ and 
luminol- $\mathrm{O}_{2}$ systems in alkaline and neutral media. Discovering of carbon nanotubes (CNTs) by Iijima [26] and surface functionalization of CNTs with nanoparticles (so called "decoration process") [27] revealed a new class of nanohybrid materials with the integrated properties of two components [28]. It seems, the application of this class of nanohybrid materials for ECL measurements provides novel opportunities for developing a new generation of (bio)sensors. Our previous studies $[13,29,30]$ obviously demonstrated that this class of nanohybrid materials noticeably improved the sensitivity of detection. The observed enhancement was attributed to the surface area and electrocatalytic activity of the nanohybrid materials which promote the rate of electron transfer reactions of luminol, oxygen and hydrogen peroxide at the electrode surface and also catalyze the generation of reactive oxygen species (ROSs) [15]. ROSs are strong oxidizing radicals and generally highly reactive species due to the presence of unpaired valence shell electron. Singlet oxygen $\left({ }^{1} \mathrm{O}_{2}\right)$, superoxide hydrogen $\left(\mathrm{HO}_{2}{ }^{\circ}\right)$, superoxide radical $\left(\mathrm{O}_{2}{ }^{*}\right)$, hydroxyl radical $\left(\mathrm{OH}^{*}\right)$ and inorganic or organic peroxides are the most well-known ROSs.

Glucose is an important carbohydrate which is introduced as a source of energy for living organisms. Its determination is vital because of its importance in clinical and industrial purposes. Rapid glucose monitoring is essential for treatment and control of diabetes. Among numerous methods which have been developed for the fast and accurate determination of glucose, electrochemical and optical based methods are the most common methods. In this context, ECL can be proposed as a powerful analytical tool for glucose detection due to its inherent sensitivity and selectivity. In an enzymatic ECL glucose biosensor, glucose oxidase (GOx) catalyzes the oxidation of glucose to gluconic acid by the reduction of molecular oxygen to the hydrogen peroxide. The enzymatically produced $\mathrm{H}_{2} \mathrm{O}_{2}$ reacts with luminol radical anion, the oxidation product of luminol at the electrode surface, and gives the excited state 3-aminophthalate anion 
which its light emission at about $425 \mathrm{~nm}$ is used for quantification of hydrogen peroxide or indirectly for glucose detection. Various nano-structured materials such as CNTs film [17], CNTs paste [31] and Au-NPs self-assembled onto a silica sol-gel network [20], $\mathrm{Fe}_{3} \mathrm{O}_{4}$-NPs [32], Au-NPs and Pd-NPs decorated CNTs [13, 30], graphene Pt nanoflower/graphene oxide [33], $\mathrm{C}_{60}$

embedded in tetraoctylammonium bromide [34], poly(luminol-aniline) nanowires [35] and hollow gold nanospheres [36] have been applied for the fabrication of glucose biosensor based on the monitoring of ECL signal of luminol.

Nano-structured Co and cobalt oxide have been widely used for the determination of biological and environmental species such as glucose [37], cysteine [38], methanol [39, 40], arsenic [41], nitrite [42] and hydrogen peroxide [43]. Our previous study reviled that cobalt nanoparticles decorated multi-walled carbon nanotubes (nanoCo-MWCNTs) is an effective nanohybrid material for the cathodic ECL measurement of luminol and dissolved oxygen [44]. In the present work, the electrocatalytic activity of nanoCo-MWCNTs on luminol ECL reaction is explored to show the feasibility of the proposed nanohybrid material for the fabrication of novel ECL (bio)sensors for luminol, $\mathrm{H}_{2} \mathrm{O}_{2}$ and glucose detection.

\section{Experimental}

\subsection{Reagents and chemicals}

All chemicals were of analytical reagent grade and used without further purification. Nafion perfluorinated ion-exchange (5\% solution in $90 \%$ light alcohol) was obtained from Fluka (Buchs, Switzerland). Luminol, Cobalt (II) acetate, sodium hydroxide, dimethylformamide (DMF) were obtained from Merck (Darmstadt, Germany). Multi-walled carbon nanotubes (95\% purity, $\mathrm{OD}=10-30 \mathrm{~nm}, \mathrm{ID}=5-10 \mathrm{~nm}$ and length $=0.5-500 \mu \mathrm{m})$ was purchased from Aldrich 
(Steinheim, Germany). Co-NPs decorated MWCNTs nanohybrid (nanoCo-MWCNTs) was prepared according to the method reported previously via manual mixing without modifications $\{$ Lin, $2009 \# 27\}$.

A $1.0 \times 10^{-2} \mathrm{M}$ stock solution of luminol (3- aminophthalhydrazide) was prepared by dissolving luminol in a small amount of $0.1 \mathrm{M} \mathrm{NaOH}$. Working solutions of luminol were prepared by diluting the stock solution with phosphate buffer solution (PBS, 0.1 M, pH=7.4). Analytical grade $\mathrm{O}_{2}$ and $\mathrm{Ar}$ gases were used for the preparation of solutions saturated with oxygen and argon gases, respectively. Phosphate buffer solution (0.1 M, pH=7.4) saturated with oxygen and argon gases were prepared separately by sparging of $\mathrm{O}_{2}$ and Ar into the PBS for at least $30 \mathrm{~min}$.

\subsection{Apparatus and procedure}

Electrochemical and ECL measurements were carried out in a $4 \mathrm{~mL}$ homemade Teflon ECL cell [30]. The working electrode was mounted in the horizontal position in the ECL cell where its surface was exactly in front of the window of a Hamamatsu photomultiplier module (H7468) (Hamamatsu city, Japan). The photodetector and ECL cell were enclosed in a light-tight black box. The electrochemical system consisted of a conventional three-electrode set-up in which nanoCo-MWCNTs modified glassy carbon electrode, a platinum wire, and an $\mathrm{Ag}|\mathrm{AgCl}| \mathrm{KCl}_{\mathrm{sat}}$ electrode served as the working, auxiliary and reference electrodes, respectively. The working potential was applied to the working electrode in the standard way using an Autolab potentiostat-galvanostat model PGSTAT30 (Utrecht, The Netherlands) and the output cyclic voltammograms and ECL signals were acquired using Autolab NOVA software and a 
home-written data acquisition program, respectively. A Metrohm $691 \mathrm{pH}$ meter was used for $\mathrm{pH}$ adjustments. All measurements were performed at room temperature.

\subsection{Fabrication of luminol, $\mathrm{H}_{2} \mathrm{O}_{2}$ and glucose ECL based (bio)sensor}

The surface of a glassy carbon electrode (GCE) was polished with $0.3,0.1$ and $0.05 \mu \mathrm{m}$ alumina past (Struers, Copenhagen, Denmark), consecutively to obtain a mirror like surface and then cleaned in water-ethanol mixture using ultrasonic agitation for 3 minutes. One milligram of nanoCo-MWCNTs was dispersed in $1 \mathrm{~mL}$ DMF with ultrasonic agitation to achieve a welldispersed suspension. $2 \mu \mathrm{L}$ of the prepared nanoCo-MWCNTs suspension was cast on the surface of GCE and dried in an oven at $50{ }^{\circ} \mathrm{C}$ to prepare GCE modified with nanoCo-MWCNTs (GCE/nanoCo-MWCNTs). The prepared sensor, GCE/nanoCo-MWCNTs, was directly used for luminol detection. Then, $5 \mu \mathrm{L}$ of Nafion solution $(0.1 \%)$ was cast on the surface of GCE/nanoCo-MWCNTs to fabricate $\mathrm{H}_{2} \mathrm{O}_{2}$ sensor (GCE/nanoCo-MWCNTs/Nafion). The prepared sensor was stored at room temperature in air when not in use. Furthermore, $2 \mu \mathrm{L}$ of

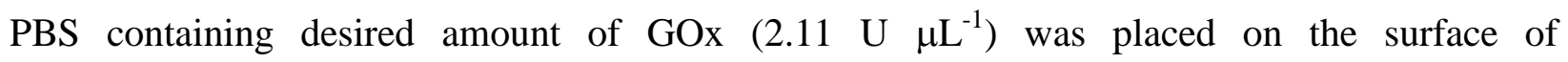
GCE/nanoCo-MWCNTs and allowed to dry at room temperature. Then, $5 \mu \mathrm{L}$ of Nafion solution $(0.1 \%)$ was cast on the surface of GCE/nanoCo-MWCNTs/GOx to fabricate glucose biosensor (GCE/nanoCo-MWCNTs/GOx/Nafion). The prepared glucose biosensor was stored at $4{ }^{\circ} \mathrm{C}$ in PBS when not in use. For comparison GCE/MWCNTs, GCE/Nafion and GCE/MWCNTs/Nafion were prepared through similar procedures.

Nafion solution was used for the fabrication of $\mathrm{H}_{2} \mathrm{O}_{2}$ sensor and also for the immobilization of GOx at the electrode surface because of its outstanding biocompatibility and excellent thermal and mechanical properties. Moreover, Nafion can induce permselectivity property against some 
compounds such as ascorbic acid, uric acid and dopamine which co-exist in the biological fluids and may interfere with glucose determination. Also, Nafion film prevents the passivation of electrode surface by side products of ECL reaction and improves the reproducibility of the ECL system.

\section{Results and discussion}

\subsection{Characterization of GCE/nanoCo-MWCNTs}

Energy dispersive X-ray spectroscopy (EDS) and transmission electron microscopy (TEM) were used to characterize the prepared nanoCo-MWCNTs (Fig. S1). The analysis of EDS profile revealed that the calculated atomic levels of carbon and cobalt were approximately similar to the applied amounts of MWCNTs and cobalt for the preparation of nanohybrid. Also, the formation of Co-NPs with an average diameter of $5 \mathrm{~nm}$ on the outer surface of MWCNTs was approved by TEM images.

The presence of Co-NPs in the prepared nanohybrid martial was approved by cyclic voltammetry $(\mathrm{CV})$ studies in alkaline solution $(\mathrm{pH}=12)$ at a scan rate of $20 \mathrm{mV} \mathrm{s}^{-1}$. Noticeable redox peaks were observed for GCE/nanoCo-MWCNTs and no redox peaks for GCE/MWCNTs and GCE (Fig. S2). The appearance of several redox peaks at different potentials was attributed to the conversion between different forms of cobalt which were stable at alkaline $\mathrm{pH}[38,39,43$, 45-47].

Charge transfer property of GCE/nanoCo-MWCNTs was also examined by $\mathrm{CV}$ and electrochemical impedance spectroscopy (EIS) using $5 \mathrm{mM} \mathrm{Fe}(\mathrm{CN})_{6}^{3-/ 4-}$ as redox couple in 0.1 $\mathrm{M} \mathrm{KCl}$ (Fig. S3). Well-defined redox peaks with peak-to-peak separation $\left(\Delta E_{\mathrm{p}}\right)$ values of 191 , 151 and $122 \mathrm{mV}$ versus $\mathrm{Ag}|\mathrm{AgCl}| \mathrm{KCl}_{\text {sat }}$ were observed for $\mathrm{Fe}(\mathrm{CN})_{6}^{3-/ 4-}$ couple at $\mathrm{GCE}$, 
GCE/MWCNTs and GCE/nanoCo-MWCNTs, respectively. Also, charge transfer resistance $\left(\mathrm{R}_{\mathrm{ct}}\right)$ values for GCE/nanoCo-MWCNTs (35 $\Omega$ ) was much less those observed for GCE/MWCNTs (75 $\Omega$ ) and GCE $(280 \Omega)$. The CV and EIS results clearly demonstrated that rate of electron transfer at GCE/nanoCo-MWCNTs was much faster than at GCE/MWCNT and GCE.

\subsection{Electrochemical and ECL investigations on luminol ECL based sensor}

Cyclic voltammograms and corresponding $\mathrm{I}_{\mathrm{ECL}}-\mathrm{E}$ curves (ECL responses) of $100 \mu \mathrm{M}$ luminol in PBS (0.1 M, pH=7.4) were recorded in the potential range between -0.3 and $0.7 \mathrm{~V}$ versus $\left(\mathrm{Ag}|\mathrm{AgCl}| \mathrm{KCl}_{\text {sat }}\right)$ with the scan rate of $100 \mathrm{mV} \mathrm{s}^{-1}$. As shown in Fig. 1, the redox peaks current, charging current and ECL response intensities recorded for luminol at GCE/nanoCOMWCNTs were much higher than those observed for luminol at GCE/MWCNTs and GCE. The value of formal potential $\left(E^{0^{\prime}}=\left(E_{\mathrm{pc}}+E_{\mathrm{pa}}\right) / 2\right.$, mean value of cathodic and anodic peak potentials $)$ for luminol at the mentioned three electrodes was about $0.5 \mathrm{~V}$, where the ECL responses of luminol at the mentioned electrodes passed over a maximum. The anodic peak current intensity of luminol at GCE/nanoCo-MWCNTs was 2 and 6 times of that observed at GCE/MWCNTs and GCE, respectively. Also, the ECL response intensity of luminol at GCE/nanoCo-MWCNTs was 3 and 5 times of that observed at GCE/MWCNTs and GCE, respectively. The observed enhancement in peak current and ECL response intensities for luminol at GCE/MWCNTs compared with GCE was attributed to the increase of electrode surface area because of the presence of MWCNTs. But, the presence of Co-NPs on the surface of the MWCNTs in the prepared nanohybrid material, nanoCo-MWCNTs, provided many active sites with higher electrocatalytic activity and sensitizing effect for the catalytic oxidation of luminol and caused to 
observe a more enhancement in peak current and ECL response at GCE/nanoCo-MWCNTs compared with GCE/MWCNTs.

Further investigation was performed on ECL behavior of luminol at the mentioned three electrodes to propose a possible mechanism for the observed ECL reaction. Potential was swept in the range between -0.3 and $0.7 \mathrm{~V}$ with the scan rate of $100 \mathrm{mV} \mathrm{s}^{-1}$ and ECL responses of 100 $\mu \mathrm{M}$ luminol in PBS (0.1 M, pH=7.4) were recorded in the absence and presence of oxygen. It was found that ECL response intensity of luminol decreased remarkably by purging of oxygen and increased significantly by sparging of oxygen, suggesting the participation of molecular $\mathrm{O}_{2}$ in ECL reaction. Also, the increase of ECL response intensity of luminol in the presence of $\mathrm{O}_{2}$ at GCE/nanoCo-MWCNTs was much higher than those of observed at GCE/MWCNTs and GCE, suggesting the catalytic action of Co-NPs in ECL reaction. Moreover, potential was swept in the range between 0 and $0.8 \mathrm{~V}$ and ECL responses of luminol were recorded at the same experimental conditions as mentioned before. It was found that the ECL response intensity at GCE/nanoCo-MWCNTs was similar to that recorded for GCE/MWCNTs with no enhancement.

Based on the results obtained in this study and those reported previously [13, 29, 44], it is proposed that the molecular oxygen is reduced by applied negative (reduction) potential and various reactive oxygen species (ROSs) is produced at the electrode surface. The chemical reaction of ROSs with the luminol radical anion, the oxidation product of luminol at $0.5 \mathrm{~V}$, produces ECL signal. It seems that the electrocatalytic activity of Co-NPs in nanoCo-MWCNTs nanohybrid martial towards $\mathrm{O}_{2}$ reduction and luminol oxidation enhances the rate of production of ROSs and luminol radical anions and consequently enhances the intensity of ECL response. The proposed mechanism was in good agreement with those reported for luminol ECL mechanism $[15,48-50]$. 
The effect of nanoCo-MWCNTs loading and potential scan rate on ECL response of luminol in PBS $(0.1 \mathrm{M}, \mathrm{pH}=7.4)$ was explored at the fixed concentrations of luminol $(100 \mu \mathrm{M})$ and dissolved oxygen $(0.29 \mathrm{mM})$. The results showed that the ECL response intensity of luminol passed over a maximum with increasing the amount of nanoCo-MWCNTs on the electrode surface. But, the ECL response intensity of luminol enhanced and reached a plateau with increasing the scan rate. The maximum ECL response was observed for $2 \mu \mathrm{L}$ of nanoCoMWCNTs (1 mg mL $\mathrm{mL}^{-1}$ ) loading (Fig. 2A) and the scan rate of $100 \mathrm{mV} \mathrm{s}^{-1}$ (Fig. 2B).

Under optimized conditions and by the sweep of potential in the range between -0.3 and $0.7 \mathrm{~V}$, the proposed GCE/nanoCo-MWCNTs was used as a sensor for determination of luminol at $\mathrm{pH}$ of 7.4 (0.1 M PBS). The ECL response of the proposed sensor was linear with the concentration of luminol in the range between $80 \mathrm{nM}$ and $140 \mu \mathrm{M}$ with a correlation coefficient of 0.9963 (Fig. 3A). The limit of detection ( $\mathrm{S} / \mathrm{N}=3$ ) for luminol was $8.7 \mathrm{nM}$. The relative standard deviations $(\mathrm{RSD})$ for repetitive measurements $(\mathrm{n}=10)$ of $100 \mu \mathrm{M}$ luminol was $1.6 \%$ (Fig. 3B).

\subsection{Electrochemical and ECL investigations on $\mathrm{H}_{2} \mathrm{O}_{2}$ ECL based sensor}

Electrochemical and ECL behaviors of luminol were investigated at GCE/nanoCOMWCNTs/Nafion in the presence $\mathrm{H}_{2} \mathrm{O}_{2}$ and in the potential range where the reduction of molecular oxygen was negligible. For this purpose, potential was swept in the range between 0 and $0.8 \mathrm{~V}$ with the scan rate of $100 \mathrm{mV} \mathrm{s}^{-1}$ and cyclic voltammograms and corresponding ECL responses of $100 \mu \mathrm{M}$ luminol were recorded in PBS $(0.1 \mathrm{M}, \mathrm{pH}=7.4)$ and in the presence of 10 $\mu \mathrm{M} \mathrm{H}_{2} \mathrm{O}_{2}$. As shown in Fig. 4, the oxidation peak current intensity and ECL response of luminol in the presence of $\mathrm{H}_{2} \mathrm{O}_{2}$ at GCE increased by modification of GCE with MWCNTs and nanoCo- 
MWCNTs nanohybrid. The ECL responses of luminol at GCE/MWCNTs/Nafion and GCE/nanoCo-MWCNTs/Nafion were 4 and 10 times of that observed at GCE/Nafion. It has been cited that the oxidation products of $\mathrm{H}_{2} \mathrm{O}_{2}$ (e.g. oxygen and superoxide radical anions) which are generated during the oxidation of $\mathrm{H}_{2} \mathrm{O}_{2}$ at the electrode surface [15] react with the luminol radical anion and produce ECL signal. In the other words, under sweeping potential in positive direction (oxidation), the immobilized nanoCo-MWCNTs on the surface of GCE catalyze the electrochemical oxidation of luminol and hydrogen peroxide. The produced luminol radical anions are further oxidized by hydrogen peroxide directly and by the oxidation products of $\mathrm{H}_{2} \mathrm{O}_{2}$ (e.g. oxygen and superoxide radical anions) to give the excited state 3-aminophthalate anions that emit light at about $425 \mathrm{~nm}$.

The effect of nanoCo-MWCNTs and Nafion loadings and potential scan rate on ECL response of luminol $(100 \mu \mathrm{M})$ was explored in PBS $(0.1 \mathrm{M}, \mathrm{pH}=7.4)$ and in the presence of 10 $\mu \mathrm{M} \mathrm{H}_{2} \mathrm{O}_{2}$. The intensity of ECL response passed over a maximum with increasing nanoCoMWCNTs and Nafion loadings. The maximum ECL response was observed for $2 \mu \mathrm{L}$ of nanoCoMWCNTs $\left(1 \mathrm{mg} \mathrm{mL}^{-1}\right)$ and $5 \mu \mathrm{L}$ Nafion $(0.1 \%)$ loadings. The effect of potential scan rate on ECL response of luminol- $\mathrm{H}_{2} \mathrm{O}_{2}$ system was similar to that observed for luminol- $\mathrm{O}_{2}$ system with a maximum ECL response at the scan rate of $100 \mathrm{mV} \mathrm{s}^{-1}$.

Under optimum experimental conditions, the proposed GCE/nanoCo-MWCNTs/Nafion was used as a sensor for determination of $\mathrm{H}_{2} \mathrm{O}_{2}$ by the sweep of potential in the range between 0 and $0.8 \mathrm{~V}$. The ECL signal of the sensor was linear with the concentration of $\mathrm{H}_{2} \mathrm{O}_{2}$ in the range between $1 \mathrm{nM}$ and $240 \mu \mathrm{M}\left(\mathrm{r}^{2}=0.9980\right)$ (Fig. 5A). The limit of detection ( $\left.\mathrm{S} / \mathrm{N}=3\right)$ for $\mathrm{H}_{2} \mathrm{O}_{2}$ was $0.2 \mathrm{nM}$. The relative standard deviations (RSD) for repetitive measurements $(\mathrm{n}=11)$ of $10 \mu \mathrm{M}$ $\mathrm{H}_{2} \mathrm{O}_{2}$ was $2.0 \%$ (Fig. 5B). 


\subsection{Electrochemical and ECL investigations on glucose ECL based biosensor}

For the fabrication of glucose ECL based biosensor (GCE/nanoCoMWCNTs/GOx/Nafion), the proposed $\mathrm{H}_{2} \mathrm{O}_{2}$ ECL based sensor, GCE/nanoCoMWCNTs/Nafion, was further modified with glucose oxidase (GOx). Preliminary investigation showed (Fig. 6) that the oxidation peak current and ECL signal intensities of luminol increased with the addition of glucose in the reaction medium. The observation of ECL emission at $425 \mathrm{~nm}$ was attributed to the reaction of luminol radical anion with $\mathrm{H}_{2} \mathrm{O}_{2}$ (the product of the enzymatic reaction of GOx and glucose) at the electrode surface. Therefore, at the optimized conditions for $\mathrm{H}_{2} \mathrm{O}_{2}$ detection, i.e. $2 \mu \mathrm{L}$ of nanoCo-MWCNTs $\left(1 \mathrm{mg} \mathrm{mL}^{-1}\right)$ and $5 \mu \mathrm{L}$ Nafion $(0.1 \%)$ loadings, the effect of GOx loading and $\mathrm{pH}$ on ECL response of luminol $(100 \mu \mathrm{M})$ at GCE/nanoCoMWCNTs/GOx/Nafion was explored in the presence of $100 \mu \mathrm{M}$ glucose and in the potential range between 0 and $0.8 \mathrm{~V}$ with the scan rate of $100 \mathrm{mV} \mathrm{s}^{-1}$.

The results showed that the ECL response of the proposed glucose biosensor in PBS $(0.1$ $\mathrm{M}, \mathrm{pH}=7.4$ ) increased with increasing the amount of GOx and then reached a plateau when $2 \mu \mathrm{L}$

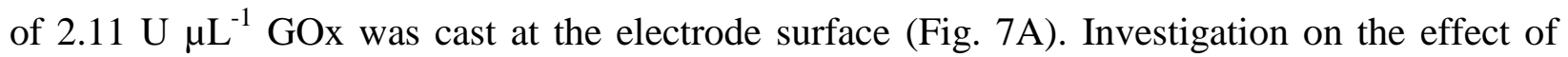
supporting electrolyte $\mathrm{pH}(\mathrm{PBS}, 0.1 \mathrm{M})$ revealed that the ECL response of the glucose biosensor increased with increasing of $\mathrm{pH}$, reached a maximum at $\mathrm{pH}$ of 9.0 and then decreased (Fig. 7B). The decline of ECL response at $\mathrm{pH}$ more than 9.0 was attributed to the decrease of GOx activity. It should be mentioned that the sensitivity of the proposed glucose biosensor in PBS $(0.1 \mathrm{M})$ at $\mathrm{pH}$ of 9.0 was higher than that observed at $\mathrm{pH}$ of 7.4. But, glucose monitoring at $\mathrm{pH}$ of 7.4, i.e. physiological $\mathrm{pH}$, is more favorable because of possible application of the biosensor for in vivo monitoring. 
The fabricated biosensor, GCE/nanoCo-MWCNTs/GOx/Nafion, was used for the determination of glucose at pHs of 7.4 and 9.0. The ECL response of the biosensor was linear with the concentration of glucose in the range between $0.5-600 \mu \mathrm{M}\left(\mathrm{r}^{2}=0.9998\right)$ at $\mathrm{pH}$ of 7.4 (Fig. 8A) and in the range between $0.1-250 \mu \mathrm{M}\left(\mathrm{r}^{2}=0.9988\right)$ at $\mathrm{pH}$ of 9.0 (Fig. 8B). The limits of detection $(\mathrm{S} / \mathrm{N}=3)$ for glucose were 50 and $20 \mathrm{nM}$ at pHs of 7.4 and 9.0, respectively. The relative standard deviations $(\mathrm{RSD})$ for repetitive measurements $(\mathrm{n}=17)$ of $100 \mu \mathrm{M}$ glucose at $\mathrm{pH}$ of 7.4 was $2.3 \%$ (Fig. 8C). The sensitivity of the proposed ECL glucose biosensor at pH of 9.0 was about 3 times of its sensitivity at $\mathrm{pH}$ of 7.4. The analytical features of some reported luminol based ECL glucose biosensors are summarized in Table 1 and compared with those obtained in this study using GCE/nanoCo-MWCNTs/GOx/Nafion.

The effects of potential interfering biological compounds such as uric acid, dopamine and ascorbic acid on the ECL response of the proposed glucose biosensor were examined. A series of solutions containing $100 \mu \mathrm{M}$ glucose plus potent interfering compounds at different concentrations were prepared. The results of the prepared test solutions were collected and compared with that obtained for the standard glucose solution. A $5 \%$ error criterion was adopted. The analysis of results showed that the tolerance of ECL signal for $100 \mu \mathrm{M}$ glucose at $\mathrm{pH}$ of 7.4 was less than $5 \%$ in the presence of $50 \mu \mathrm{M}$ uric acid, $10 \mu \mathrm{M}$ dopamine and $5 \mu \mathrm{M}$ ascorbic acid. Uric acid, dopamine and ascorbic at the concentrations more than $50 \mu \mathrm{M}$ decreased the ECL intensity of glucose. The obtained results are summarized in Table 2.

The applicability of the proposed glucose ECL biosensor was also examined by the determination of glucose in normal human serum sample. $3 \mu \mathrm{L}$ of normal human serum sample was mixed with $3 \mathrm{~mL}$ PBS $(0.1 \mathrm{M}, \mathrm{pH}=7.4)$ containing $100 \mu \mathrm{M}$ luminol and certain amount of glucose $(0,10,30,50$ or $100 \mu \mathrm{M})$. The prepared solutions were then examined using 
GCE/nanoCo-MWCNTs/GOx/Nafion. The concentration of glucose in normal human serum determined by the use of proposed glucose biosensor and by local hospital was 4.71 and 4.83 $\mathrm{mM}$, respectively. The recovery of the analysis was about $97.5 \%$. Recoveries for the five spiked samples were between $97 \%$ and $105 \%$.

\section{Conclusions}

An economical nanohybrid material, nanoCo-MWCNTs, was prepared using a facile and rapid approach. The prepared nanohybrid material was successfully applied for the fabrication of a novel ECL based (bio)sensor for the determination of luminol, $\mathrm{H}_{2} \mathrm{O}_{2}$ and glucose. The fabricated ECL (bio)sensor showed strong sensitizing effect on the ECL response of luminol due to the excellent electrocatalytic activity of nanoCo-MWCNTs towards $\mathrm{O}_{2}$ reduction and luminol and $\mathrm{H}_{2} \mathrm{O}_{2}$ oxidation reactions. The analysis of results indicated that the proposed nanohybrid material and fabricated (bio)sensor have a great potential for practical applications.

\section{Acknowledgments}

The authors acknowledge the Institute for Advanced Studies in Basic Science (IASBS, grant number G2015IASBS119), the Iran National Science Foundation (INSF, grant number 90006781) for and the Iran National Elite Foundation (INEF) for the financial supports. 


\section{Legend for figures}

Fig. 1. A) Cyclic voltammograms and B) corresponding ECL responses of luminol at a GCE (dotted line), GCE/MWCNTs (dashed line) and GCE/nanoCO-MWCNTs (solid line). Conditions: luminol, $100 \mu \mathrm{M}$; supporting electrolyte, PBS (0.1M and $\mathrm{pH} 7.4)$; potential scan rate, $100 \mathrm{mV} \mathrm{s}^{-1}$.

Fig. 2. Effect of A) nanoCo-MWCNTs loading and B) scan rate on the ECL response of luminol at GCE/nanoCO-MWCNTs. Conditions: luminol, $100 \mu \mathrm{M}$; supporting electrolyte, PBS (0.1M and $\mathrm{pH} 7.4)$; potential scan rate for $\mathrm{A}, 100 \mathrm{mV} \mathrm{s}^{-1}$.

Fig. 3. A) Calibration plot of ECL response versus luminol concentration and B) reproducibility of ECL responses for $100 \mu \mathrm{M}$ luminol at GCE/nanoCo-MWCNTs/Nafion. Conditions: supporting electrolyte, $\mathrm{PBS}(0.1 \mathrm{M}$ and $\mathrm{pH} 7.4)$; potential scan rate, $100 \mathrm{mV} \mathrm{s}^{-1}$.

Fig. 4. A) Cyclic voltammograms and B) corresponding ECL responses of luminol at a GCE/Nafion (dotted line), GCE/MWCNTs/Nafion (dashed line) and GCE/nanoCOMWCNTs/Nafion (solid line) in the presence of $10 \mu \mathrm{M} \mathrm{H}_{2} \mathrm{O}_{2}$. Conditions: luminol, 100 $\mu \mathrm{M}$; supporting electrolyte, $\mathrm{PBS}(0.1 \mathrm{M}$ and $\mathrm{pH} 7.4)$; potential scan rate, $100 \mathrm{mV} \mathrm{s}^{-1}$.

Fig. 5. A) Calibration plot of ECL response versus $\mathrm{H}_{2} \mathrm{O}_{2}$ concentration and B) reproducibility of ECL responses for $10 \mu \mathrm{M} \mathrm{H}_{2} \mathrm{O}_{2}$ at GCE/nanoCo-MWCNTs/Nafion. Conditions: Luminol, $100 \mu \mathrm{M}$; supporting electrolyte, PBS (0.1 M and $\mathrm{pH} 7.4)$; potential scan rate, $100 \mathrm{mV} \mathrm{s}^{-1}$.

Fig. 6. A) Cyclic voltammograms and B) corresponding ECL responses of luminol at GCE/nanoCo-MWCNTs/GOx/Nafion in the absence (dashed line) and presence (solid 
line) of $100 \mu \mathrm{M}$ glucose. Conditions: luminol, $100 \mu \mathrm{M}$; supporting electrolyte, PBS (0.1M and $\mathrm{pH} 7.4)$; potential scan rate, $100 \mathrm{mV} \mathrm{s}^{-1}$.

Fig. 7. Effect of A) GOx loading and B) pH on the ECL response of luminol at GCE/nanoCOMWCNTs/GOx/Nafion. Conditions: glucose, $100 \mu \mathrm{M}$; luminol, $100 \mu \mathrm{M}$; supporting electrolyte, PBS (0.1M and $\mathrm{pH} 7.4)$; potential scan rate for $\mathrm{A}, 100 \mathrm{mV} \mathrm{s}^{-1}$.

Fig. 8. A) Calibration plot of ECL response versus glucose concentration in $0.1 \mathrm{M} P B S$ at $\mathrm{pH}$ of 7.4, B) at $\mathrm{pH}$ of 9 and C) reproducibility of ECL responses for $100 \mu \mathrm{M}$ glucose at GCE/nanoCo-MWCNTs/GOx/Nafion. Conditions: Luminol, $100 \mu \mathrm{M}$; supporting electrolyte, PBS (0.1 M and pH 7.4 for reproducibility); potential scan rate, $100 \mathrm{mV} \mathrm{s}^{-1}$. 


\section{References}

[1] A.J. Bard, Electrogenerated chemiluminescence, Taylor and Francis, 2004.

[2] J. Wang, G. Liu, H. Wu, Y. Lin, Quantum dot based electrochemical immunoassay for high throughput screening of the prostate specific antigen, Small, 4 (2007) 82-86.

[3] L. Hu, G. Xu, Applications and trends in electrochemiluminescence, Chem. Soc. Rev., 39 (2010) 3275-3304.

[4] R.A. Hewes, M.V. Hoffman, $4 \mathrm{f}^{7}-4 \mathrm{f}^{7}$ emission from $\mathrm{Eu}^{2+}$ in the system $\mathrm{MF}_{2} \cdot \mathrm{AlF}_{3}, \mathrm{~J}$. Lumin., 3 (1971) 261-280.

[5] G.M. Greenway, Analytical applications of electrogenerated chemiluminescence, TrAC, Trends Anal. Chem., 9 (1990) 200-203.

[6] J.G. Velasco, Electroluminescence, Electroanalysis, 3 (1991) 261-271.

[7] A.W. Knight, G.M. Greenway, Occurrence, mechanisms and analytical applications of electrogenerated chemiluminescence: A review, Analyst, 119 (1994) 879-890.

[8] W. Miao, Electrogenerated chemiluminescence and its biorelated applications, Chem. Rev., 108 (2008) 2506-2553.

[9] M.M. Richter, Electrochemiluminescence (ecl), Chem. Rev., 104 (2004) 3003-3036.

[10] V. Vojir, Chemilumineszenz um die Quecksilbertropfelektrode, Coll. Czech. Chem. Commun., 19 (1954) 868-872.

[11] P. Bertoncello, R.J. Forster, Nanostructured materials for electrochemiluminescence (ECL)-based detection methods: Recent advances and future perspectives, Biosens. Bioelectron., 24 (2009) 3191-3200.

[12] W. Guo, J. Yan, Y. Tu, The intensification of luminol electrochemiluminescence by metallic oxide nanoparticles, Sci. China Chem., 54 (2011) 1640-1644. 
[13] B. Haghighi, S. Bozorgzadeh, Enhanced electrochemiluminescence from luminol at multiwalled carbon nanotubes decorated with palladium nanoparticles: A novel route for the fabrication of an oxygen sensor and a glucose biosensor, Anal. Chim. Acta, 697 (2011) 9097.

[14] W. Xiuhua, L. Chao, T. Yifeng, Microemulsion-enhanced electrochemiluminescence of luminol- $\mathrm{H}_{2} \mathrm{O}_{2}$ for sensitive flow injection analysis of antioxidant compounds, Talanta, 94 (2012) 289-294.

[15] H. Chu, W. Guo, J. Di, Y. Wu, Y. Tu, Study on sensitization from reactive oxygen species for electrochemiluminescence of luminol in neutral medium, Electroanalysis, 21 (2009) $1630-1635$.

[16] B. Qiu, Z. Lin, J. Wang, Z. Chen, J. Chen, G. Chen, An electrochemiluminescent biosensor for glucose based on the electrochemiluminescence of luminol on the nafion/glucose oxidase/poly (nickel (II) tetrasulfophthalocyanine)/multi-walled carbon nanotubes modified electrode, Talanta, 78 (2009) 76-80.

[17] Z. Lin, J. Chen, G. Chen, An ECL biosensor for glucose based on carbon-nanotube/Nafion film modified glass carbon electrode, Electrochim. Acta, 53 (2008) 2396-2401.

[18] Y.-P. Dong, H. Cui, C.-M. Wang, Electrogenerated chemiluminescence of luminol on a gold-nanorod-modified gold electrode, J. Phys. Chem. B, 110 (2006) 18408-18414.

[19] Y.-P. Dong, H. Cui, Y. Xu, Comparative studies on electrogenerated chemiluminescence of luminol on gold nanoparticle modified electrodes, Langmuir, 23 (2007) 523-529.

[20] X. Liu, W. Niu, H. Li, S. Han, L. Hu, G. Xu, Glucose biosensor based on gold nanoparticle-catalyzed luminol electrochemiluminescence on a three-dimensional sol-gel network, Electrochem. Commun., 10 (2008) 1250-1253. 
[21] X. Chen, Z. Lin, Z. Cai, M. Oyama, X. Wang, Electrochemiluminescence of luminol on a platinum-nanoparticle-modified indium tin oxide electrode in neutral aqueous solution, $\mathrm{J}$. Nanosci. Nanotechnol., 9 (2009) 2413-2420.

[22] C.M. Wang, H. Cui, Electrogenerated chemiluminescence of luminol in neutral and alkaline aqueous solutions on a silver nanoparticle self-assembled gold electrode, Luminescence, 22 (2007) 35-45.

[23] J.-Z. Guo, H. Cui, W. Zhou, W. Wang, Ag nanoparticle-catalyzed chemiluminescent reaction between luminol and hydrogen peroxide, J. Photochem. Photobiol., A, 193 (2008) 89-96.

[24] B. Haghighi, S. Bozorgzadeh, Flow injection chemiluminescence determination of isoniazid using luminol and silver nanoparticles, Microchem. J., 95 (2010) 192-197.

[25] H. Dai, Y. Chi, X. Wu, Y. Wang, M. Wei, G. Chen, Biocompatible electrochemiluminescent biosensor for choline based on enzyme/titanate nanotubes/chitosan composite modified electrode, Biosens. Bioelectron., 25 (2010) 14141419.

[26] S. Iijima, Helical microtubules of graphitic carbon, Nature, 354 (1991) 56-58.

[27] Y. Lin, K.A. Watson, M.J. Fallbach, S. Ghose, J.G. Smith Jr, D.M. Delozier, W. Cao, R.E. Crooks, J.W. Connell, Rapid, solventless, bulk preparation of metal nanoparticle-decorated carbon nanotubes, ACS Nano, 3 (2009) 871-884.

[28] V. Georgakilas, D. Gournis, V. Tzitzios, L. Pasquato, D.M. Guldi, M. Prato, Decorating carbon nanotubes with metal or semiconductor nanoparticles, J. Mater. Chem., 17 (2007) 2679-2694. 
[29] B. Haghighi, S. Bozorgzadeh, Fabrication of a highly sensitive electrochemiluminescence lactate biosensor using $\mathrm{ZnO}$ nanoparticles decorated multiwalled carbon nanotubes, Talanta, 85 (2011) 2189-2193.

[30] B. Haghighi, S. Bozorgzadeh, L. Gorton, Fabrication of a novel electrochemiluminescence glucose biosensor using Au nanoparticles decorated multiwalled carbon nanotubes, Sensor. Actuat. B-Chem., 155 (2011) 577-583.

[31] J. Chen, Z. Lin, G. Chen, An electrochemiluminescent sensor for glucose employing a modified carbon nanotube paste electrode, Anal. Bioanal. Chem., 388 (2007) 399-407.

[32] Z.-G. Xiong, J.-P. Li, L. Tang, Z.-Q. Chen, A novel electrochemiluminescence biosensor based on glucose oxidase immobilized on magnetic nanoparticles, Chinese J. Anal. Chem., 38 (2010) 800-804.

[33] X. Tian, S. Lian, L. Zhao, X. Chen, Z. Huang, X. Chen, A novel electrochemiluminescence glucose biosensor based on platinum nanoflowers/graphene oxide/glucose oxidase modified glassy carbon electrode, J. Solid State Electrochem., 18 (2014) 2375-2382.

[34] C. Ye, X. Zhong, R. Yuan, Y. Chai, A novel ECL biosensor based on C60 embedded in tetraoctylammonium bromide for the determination of glucose, Sensor. Actuat. B-Chem., 199 (2014) 101-107.

[35] G. Li, J. Lian, X. Zheng, J. Cao, Electrogenerated chemiluminescence biosensor for glucose based on poly(luminol-aniline) nanowires composite modified electrode, Biosens. Bioelectron., 26 (2010) 643-648.

[36] X. Zhong, Y.Q. Chai, R. Yuan, A novel strategy for synthesis of hollow gold nanosphere and its application in electrogenerated chemiluminescence glucose biosensor, Talanta, 128 (2014) 9-14. 
[37] I.G. Casella, M.R. Guascito, Anodic electrodeposition of conducting cobalt oxyhydroxide films on a gold surface. XPS study and electrochemical behaviour in neutral and alkaline solution, J. Electroanal. Chem., 476 (1999) 54-63.

[38] I.G. Casella, M. Gatta, Study of the electrochemical deposition and properties of cobalt oxide species in citrate alkaline solutions, J. Electroanal. Chem., 534 (2002) 31-38.

[39] M. Jafarian, M. Mahjani, H. Heli, F. Gobal, H. Khajehsharifi, M. Hamedi, A study of the electro-catalytic oxidation of methanol on a cobalt hydroxide modified glassy carbon electrode, Electrochim. Acta, 48 (2003) 3423-3429.

[40] H. Zhao, L. Li, J. Yang, Y. Zhang, Co@Pt-Ru core-shell nanoparticles supported on multiwalled carbon nanotube for methanol oxidation, Electrochem. Commun., 10 (2008) $1527-1529$.

[41] A. Salimi, H. Mamkhezri, R. Hallaj, S. Soltanian, Electrochemical detection of trace amount of arsenic (III) at glassy carbon electrode modified with cobalt oxide nanoparticles, Sensor. Actuat. B-Chem., 129 (2008) 246-254.

[42] A. Salimi, R. Hallaj, H. Mamkhezri, S.M.T. Hosaini, Electrochemical properties and electrocatalytic activity of FAD immobilized onto cobalt oxide nanoparticles: Application to nitrite detection, J. Electroanal. Chem., 619 (2008) 31-38.

[43] A. Salimi, R. Hallaj, S. Soltanian, H. Mamkhezri, Nanomolar detection of hydrogen peroxide on glassy carbon electrode modified with electrodeposited cobalt oxide nanoparticles, Anal. Chim. Acta, 594 (2007) 24-31.

[44] B. Haghighi, A. Tavakoli, S. Bozorgzadeh, Cathodic electrogenerated chemiluminescence of luminol on glassy carbon electrode modified with cobalt nanoparticles decorated multiwalled carbon nanotubes, Electrochim. Acta, 154 (2015) 259-265. 
[45] S. Floate, M. Hyde, R.G. Compton, Electrochemical and AFM studies of the electrodeposition of cobalt on glassy carbon: an analysis of the effect of ultrasound, J. Electroanal. Chem., 523 (2002) 49-63.

[46] N. Spataru, C. Terashima, K. Tokuhiro, I. Sutanto, D.A. Tryk, S.-M. Park, A. Fujishima, Electrochemical behavior of cobalt oxide films deposited at conductive diamond electrodes, J. Electrochem. Soc., 150 (2003) E337-E341.

[47] C. Barbero, G.A. Planes, M.C. Miras, Redox coupled ion exchange in cobalt oxide films, Electrochem. Commun., 3 (2001) 113-116.

[48] H. Cui, G.-Z. Zou, X.-Q. Lin, Electrochemiluminescence of luminol in alkaline solution at a paraffin-impregnated graphite electrode, Anal. Chem., 75 (2003) 324-331.

[49] S. Sakura, Electrochemiluminescence of hydrogen peroxide-luminol at a carbon electrode, Anal. Chim. Acta, 262 (1992) 49-57.

[50] H. Cui, Y. Xu, Z.-F. Zhang, Multichannel electrochemiluminescence of luminol in neutral and alkaline aqueous solutions on a gold nanoparticle self-assembled electrode, Anal. Chem., 76 (2004) 4002-4010.

[51] X. Chen, H. Ye, W. Wang, B. Qiu, Z. Lin, G. Chen, Electrochemiluminescence biosensor for glucose based on Graphene/Nafion/GOD film modified glassy carbon electrode, Electroanalysis, 22 (2010) 2347-2352.

[52] C.A. Marquette, L.c.J. Blum, Luminol electrochemiluminescence-based fiber optic biosensors for flow injection analysis of glucose and lactate in natural samples, Anal. Chim. Acta, 381 (1999) 1-10. 
[53] L. Zhu, Y. Li, F. Tian, B. Xu, G. Zhu, Electrochemiluminescent determination of glucose with a sol-gel derived ceramic-carbon composite electrode as a renewable optical fiber biosensor, Sensor. Actuat. B-Chem., 84 (2002) 265-270.

[54] L. Zhu, Y. Li, G. Zhu, A novel flow through optical fiber biosensor for glucose based on luminol electrochemiluminescence, Sensor. Actuat. B-Chem., 86 (2002) 209-214.

[55] B.P. Corgier, C.A. Marquette, L.J. Blum, Screen-printed electrode microarray for electrochemiluminescent measurements, Anal. Chim. Acta, 538 (2005) 1-7.

[56] H. Dai, X. Wu, H. Xu, Y. Wang, Y. Chi, G. Chen, A highly performing electrochemiluminescent biosensor for glucose based on a polyelectrolyte-chitosan modified electrode, Electrochim. Acta, 54 (2009) 4582-4586. 
Table 1. Analytical features reported for some luminol based ECL glucose biosensors.

\begin{tabular}{|c|c|c|c|c|}
\hline Modified electrode & $\overline{\operatorname{LDR}(\mu \mathrm{M})}$ & $\mathrm{DL}(\mu \mathrm{M})$ & $\mathrm{pH}$ & Reference \\
\hline CNTPE & $1-2000$ & 0.5 & 7.0 & {$[31]$} \\
\hline GCE/CNTs/Nafion & $5-80$ & 2 & 7.4 & [17] \\
\hline $\mathrm{Au} /$ sol-gel/AuNPs & $1-5000$ & 0.2 & 7.5 & [20] \\
\hline GCE/MWCNTs/polyNiTSPc/Nafion & $1-100$ & 0.08 & 7.4 & [16] \\
\hline $\mathrm{SCPE} / \mathrm{Fe}_{3} \mathrm{O}_{4}$ & $10-10000$ & 1 & 8.0 & [32] \\
\hline GCE/Graphene/Nafion & $2-100$ & 1 & 7.4 & [51] \\
\hline GE/PLANC & $0.1-50$ & 0.03 & 9.0 & [35] \\
\hline GCE/collagen membrane & $0.6-3000^{\mathrm{a}}$ & $0.06^{\mathrm{a}}$ & 8.5 & {$[52]$} \\
\hline GCE/polyamide membrane & $1.5-300^{\mathrm{a}}$ & $1.5^{\mathrm{a}}$ & 8.5 & [52] \\
\hline GCE/sol-gel matrix & $50-10000$ & 26 & 9.0 & [53] \\
\hline $\mathrm{CCE}$ & $10-10000$ & 8.16 & 8.5 & [54] \\
\hline SP graphite electrode microarrays & $3-3000$ & 3 & $\mathrm{nr}$ & [55] \\
\hline GCE/PDDA-CS & $0.0005-40$ & 0.0001 & 7.5 & [56] \\
\hline \multirow[t]{2}{*}{ GCE/AuNPs-MWCNTs/CS } & $1-1000$ & 0.5 & 7.4 & [29] \\
\hline & $0.5-110$ & 0.06 & 8.5 & \\
\hline GCE/nanoPd-MWCNTs/Nafion & $0.1-1000$ & 0.054 & 7.4 & [13] \\
\hline GCE/PtNFs/GO & $5-1000$ & 2.8 & 7.4 & [33] \\
\hline \multirow[t]{2}{*}{ GCE/nanoCo-MWCNTs/Nafion } & $0.5-600$ & 0.05 & 7.4 & This work \\
\hline & $0.1-250$ & 0.02 & 9.0 & \\
\hline
\end{tabular}


Table 2. The effect of potential interfering compounds on the ECL signal intensity of $100 \mu \mathrm{M}$ glucose.

\begin{tabular}{|c|c|c|c|}
\hline $\begin{array}{l}\text { Interfering } \\
\text { compounds }\end{array}$ & $\begin{array}{c}\text { [interference] } \\
(\mu \mathrm{M})\end{array}$ & $\begin{array}{c}\text { Average ECL signal } \\
\text { (arbitrary unit) }\end{array}$ & $\begin{array}{c}\text { Recovery (RSD for } \mathrm{n}=5 \\
(\%)\end{array}$ \\
\hline \multirow{4}{*}{ Ascorbic acid } & 0 & 50.5 & $100(0.7)$ \\
\hline & 1 & 49 & $98(0.6)$ \\
\hline & 5 & 48 & $95(0.9)$ \\
\hline & 0 & 51.1 & $100(0.4)$ \\
\hline \multirow{3}{*}{ Dopamine } & 1 & 50.7 & $99(0.3)$ \\
\hline & 5 & 50.1 & $98(0.7)$ \\
\hline & 10 & 48.6 & $95(0.5)$ \\
\hline \multirow{5}{*}{ Uric Acid } & 0 & 49.9 & $100(0.4)$ \\
\hline & 1 & 49.6 & $99(0.2)$ \\
\hline & 5 & 49.4 & $99(0.4)$ \\
\hline & 10 & 48.6 & $97(0.7)$ \\
\hline & 50 & 47.5 & $95(0.8)$ \\
\hline
\end{tabular}



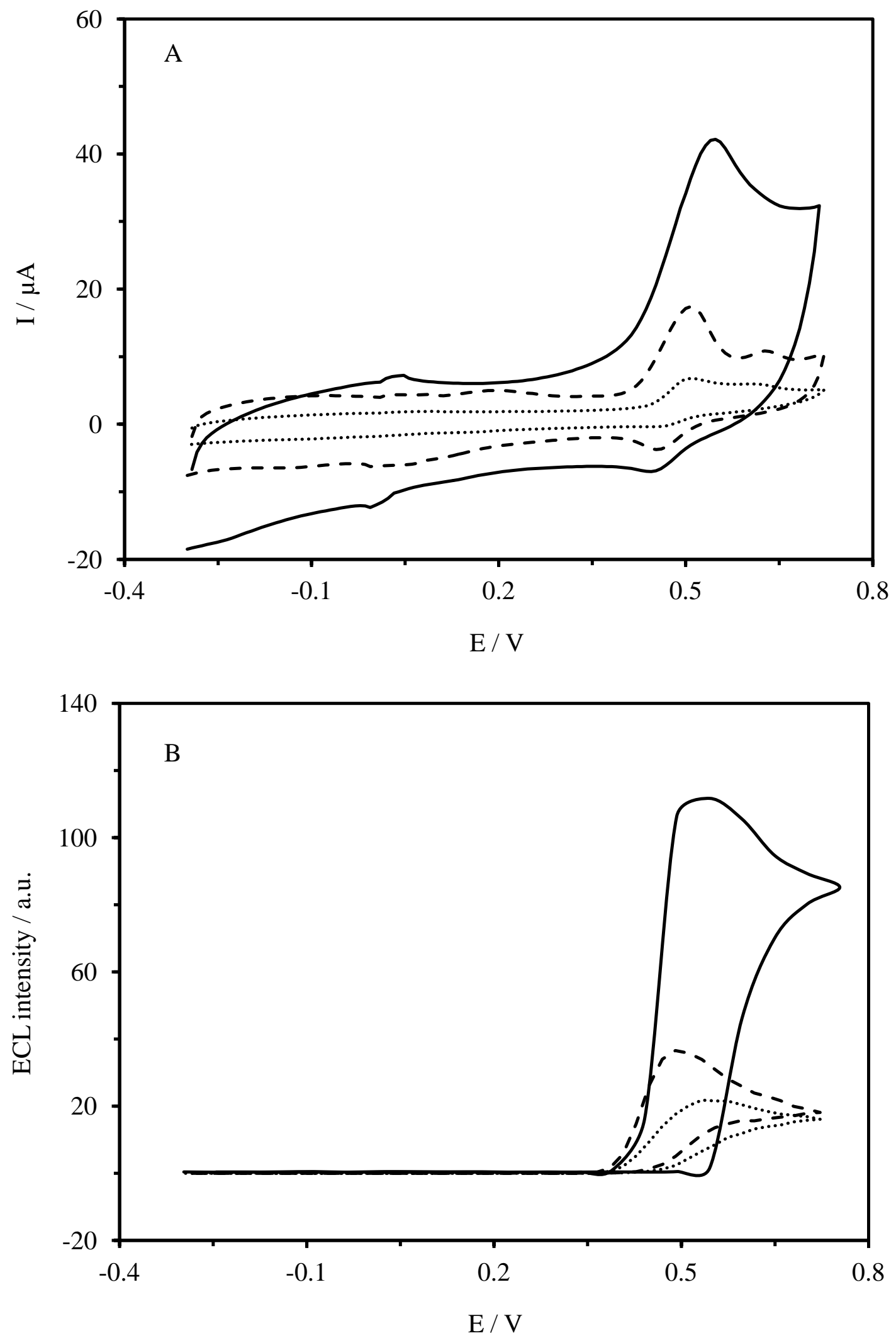

Fig. 1 

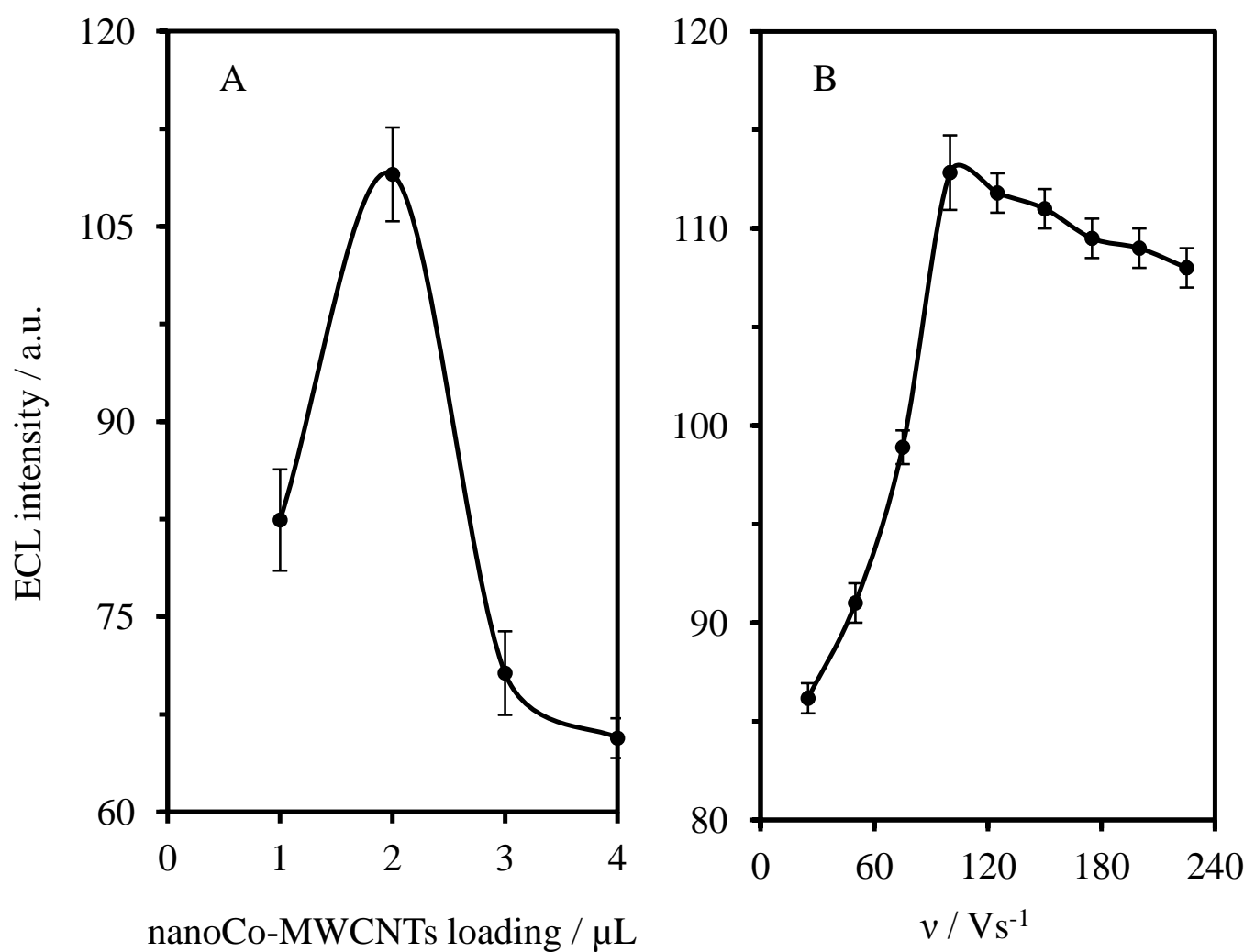

Fig. 2 

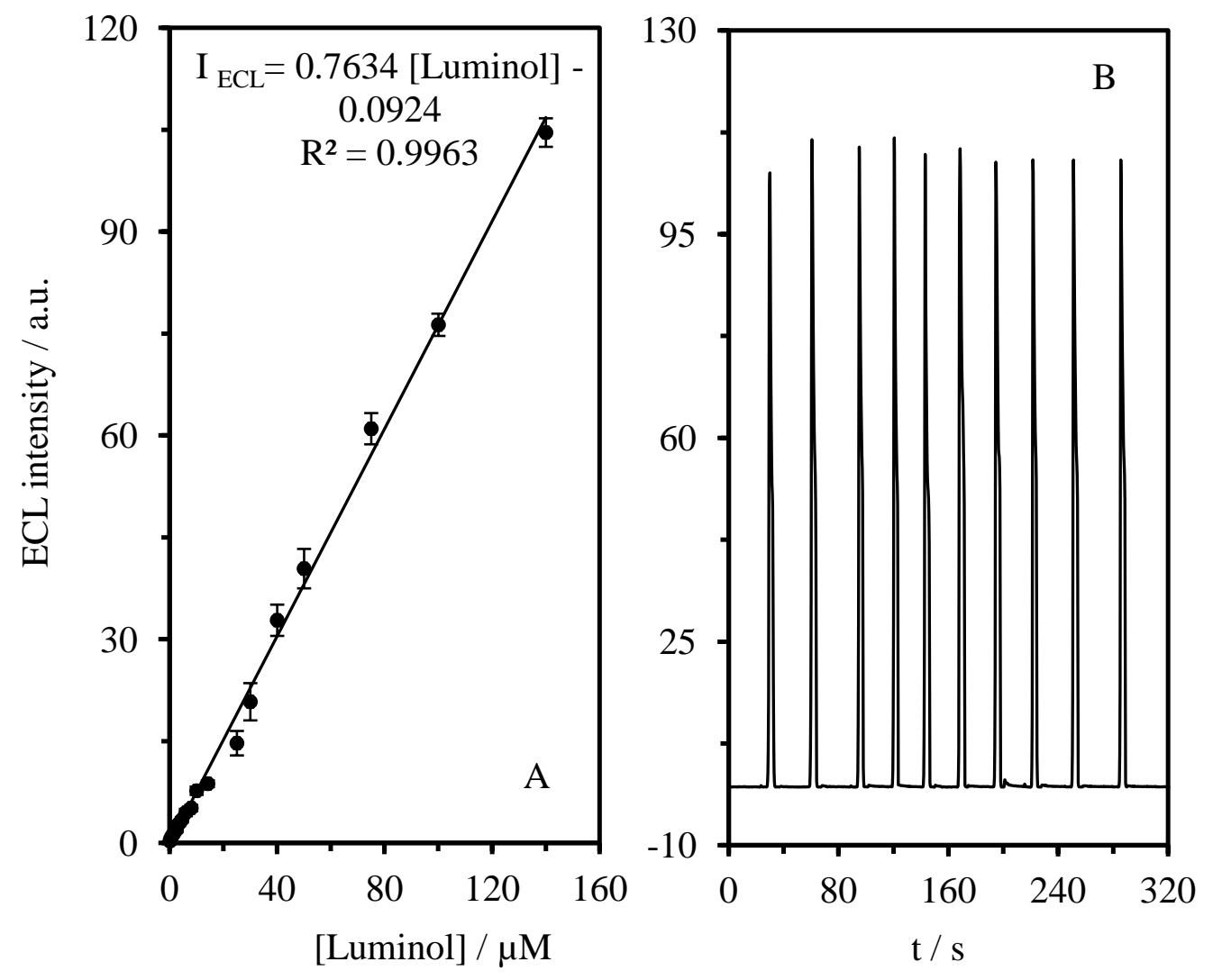

Fig. 3 

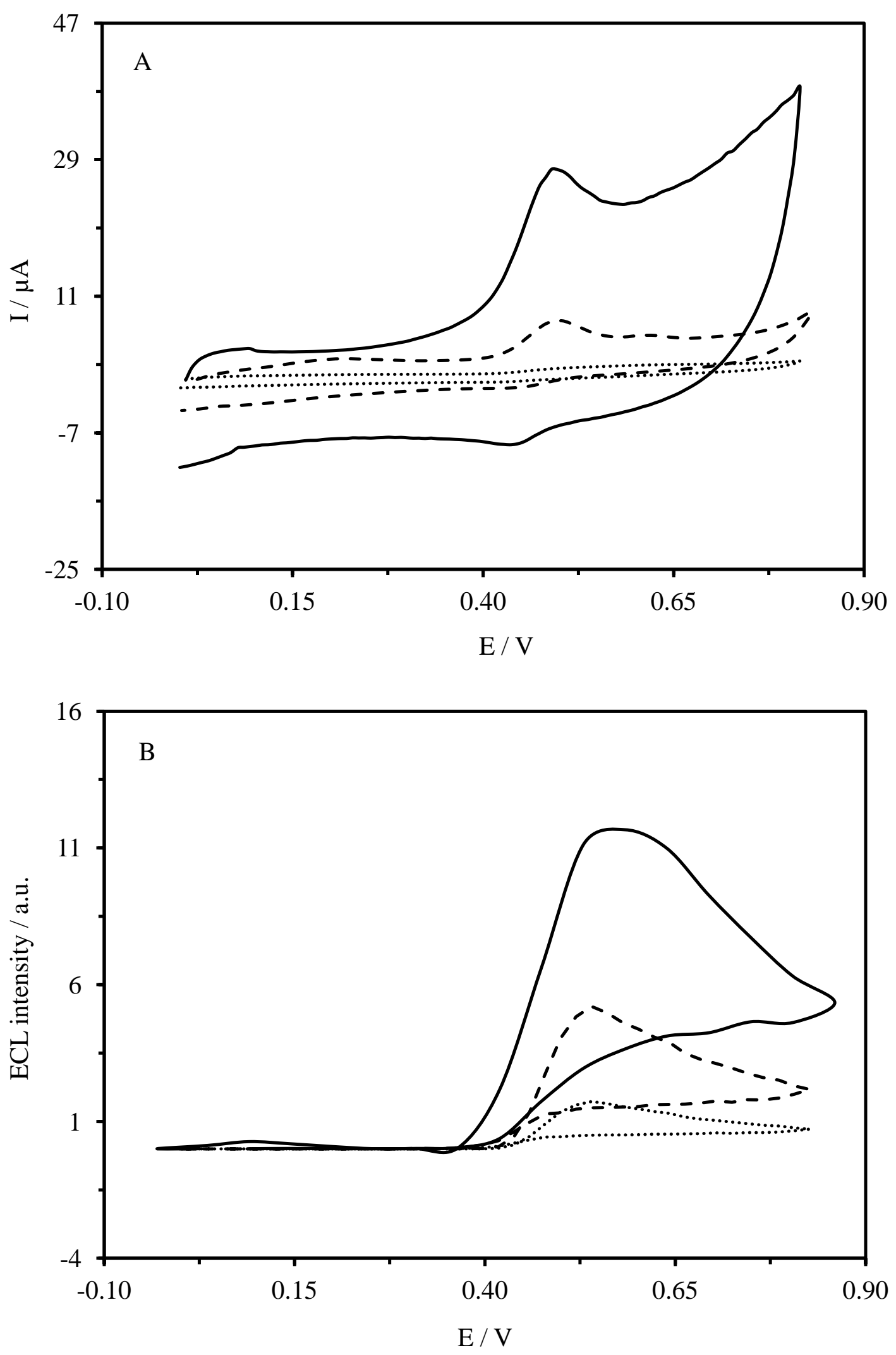

Fig. 4 

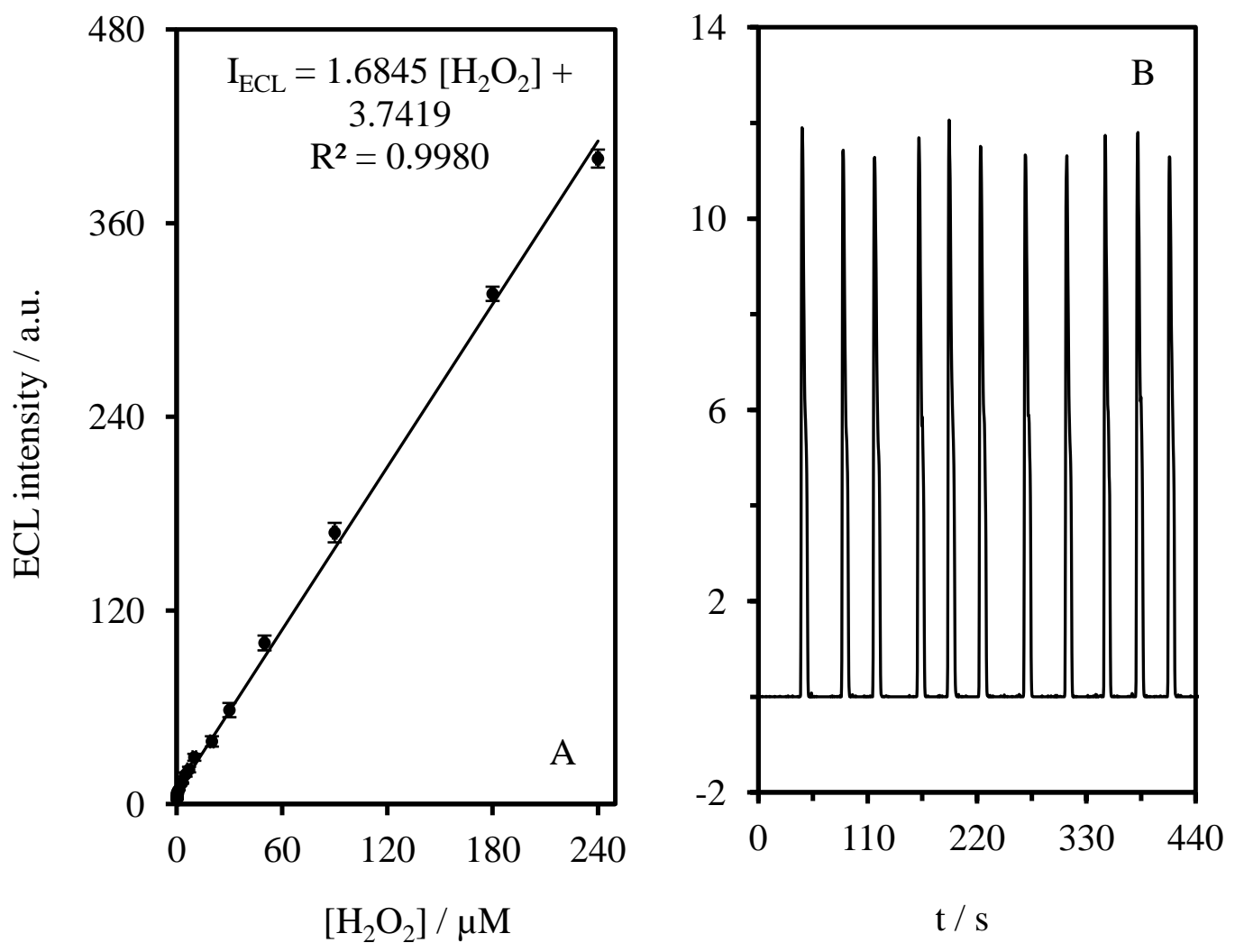

Fig. 5 

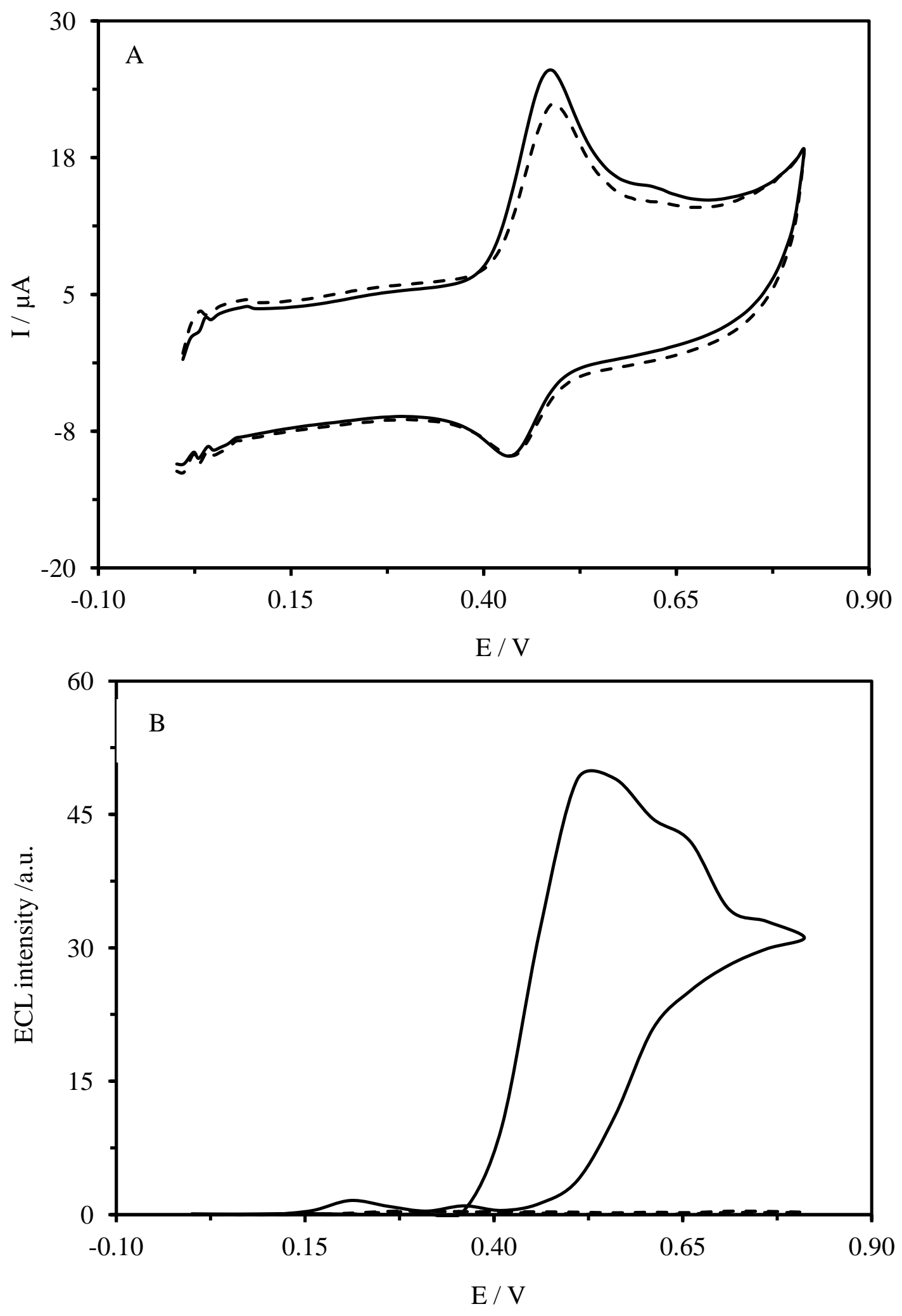

Fig. 6 

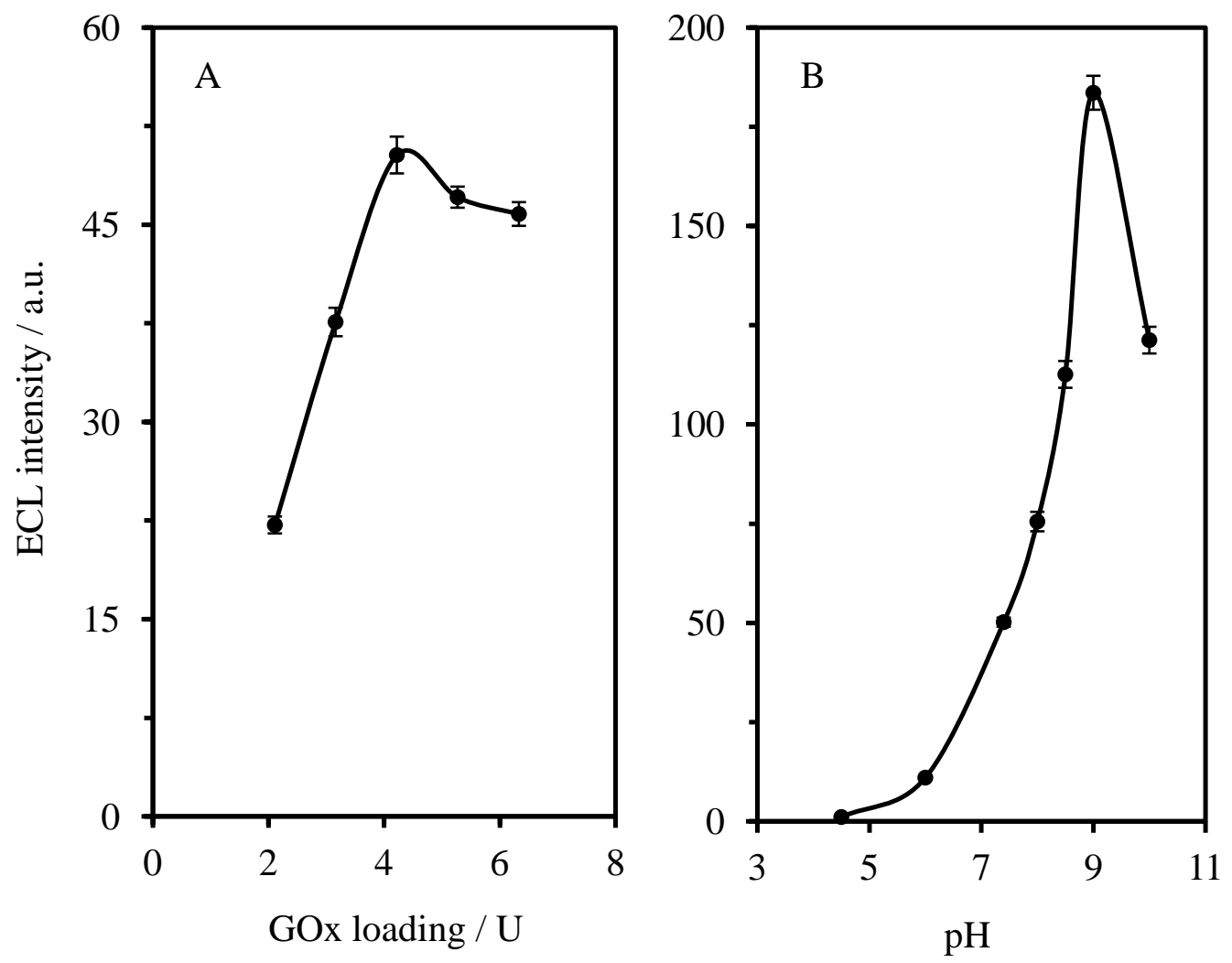

Fig. 7 

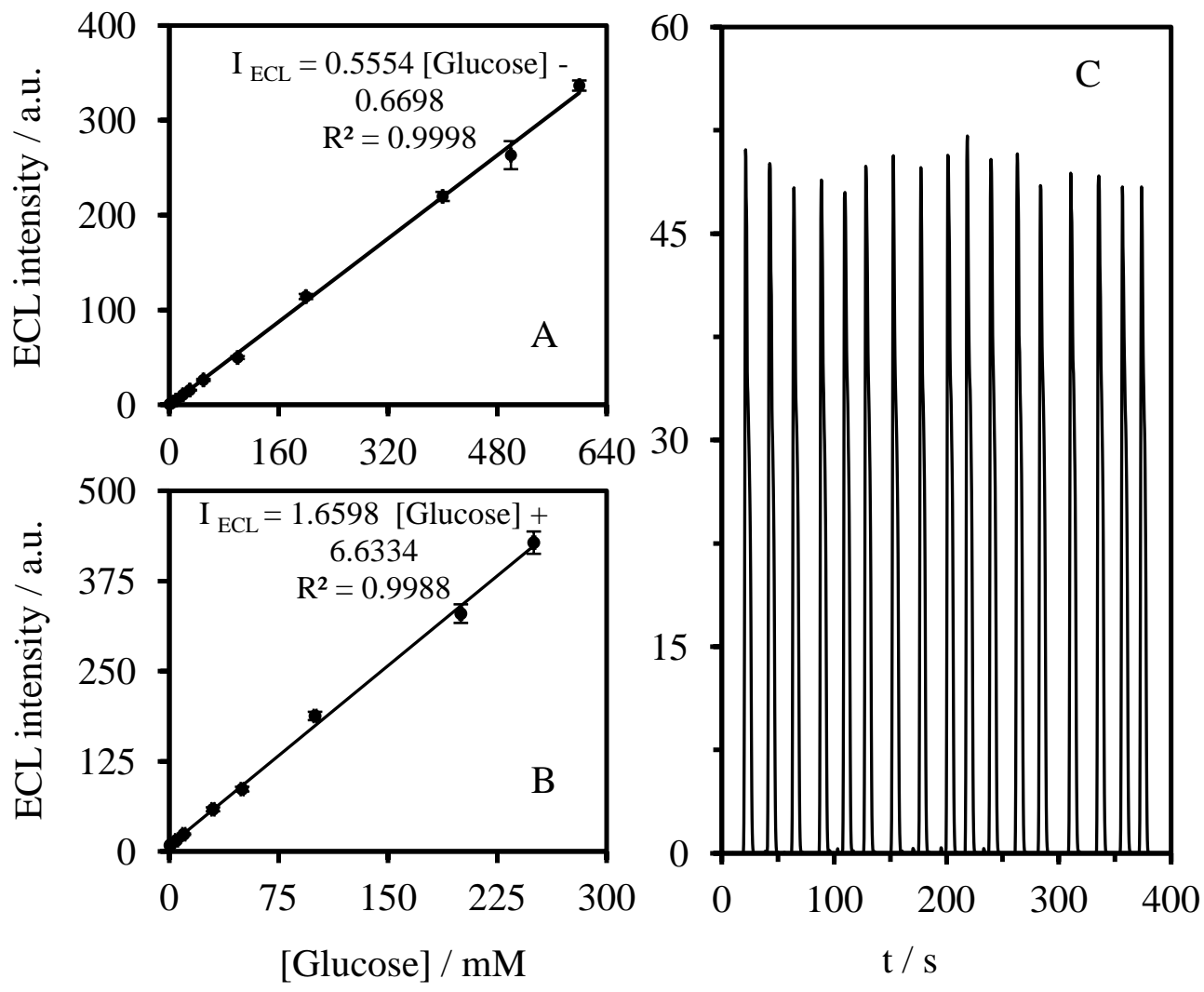

Fig. 8 